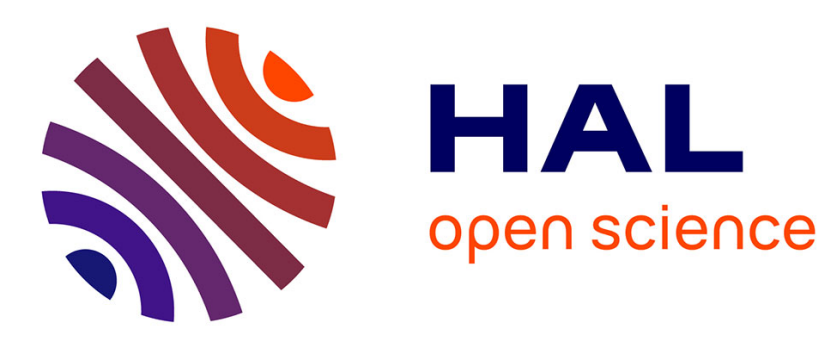

\title{
Local configurations on surfaces of icosahedral quasicrystals
}

Gerald Kasner, Zorka Papadopolos

\section{To cite this version:}

Gerald Kasner, Zorka Papadopolos. Local configurations on surfaces of icosahedral quasicrystals. Philosophical Magazine, 2006, 86 (06-08), pp.813-818. 10.1080/14786430500268628 . hal-00513587

\section{HAL Id: hal-00513587 \\ https://hal.science/hal-00513587}

Submitted on 1 Sep 2010

HAL is a multi-disciplinary open access archive for the deposit and dissemination of scientific research documents, whether they are published or not. The documents may come from teaching and research institutions in France or abroad, or from public or private research centers.
L'archive ouverte pluridisciplinaire HAL, est destinée au dépôt et à la diffusion de documents scientifiques de niveau recherche, publiés ou non, émanant des établissements d'enseignement et de recherche français ou étrangers, des laboratoires publics ou privés. 


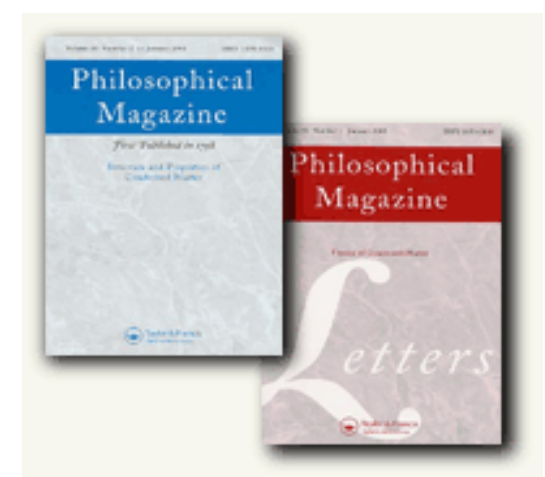

\section{Local configurations on surfaces of icosahedral quasicrystals}

\begin{tabular}{|c|c|}
\hline Journal: & Philosophical Magazine \& Philosophical Magazine Letters \\
\hline Manuscript ID: & TPHM-05-May-0205.R1 \\
\hline Journal Selection: & Philosophical Magazine \\
\hline $\begin{array}{r}\text { Date Submitted by the } \\
\text { Author: }\end{array}$ & 06-Jul-2005 \\
\hline Complete List of Authors: & $\begin{array}{l}\text { Kasner, Gerald; Otto-von-Guericke Universität Magdeburg, Institut } \\
\text { für Theoretische Physik } \\
\text { Papadopolos, Zorka; Eberhard-Karls Universität Tübingen, Institut } \\
\text { für Theoretische Physik }\end{array}$ \\
\hline Keywords: & surface properties, surface analysis, STM, quasicrystals \\
\hline Keywords (user supplied): & \\
\hline
\end{tabular}

\section{(5) ScholarONE \\ Manuscript Central}




\title{
Local configurations on surfaces of icosahedral quasicrystals
}

\author{
G. KASNER ${ }^{*} \dagger$ and Z. PAPADOPOLOS $\ddagger$ \\ $\dagger$ Institut für Theoretische Physik, Otto-von-Guericke-Universität \\ Universitätsplatz 2, PF 4120, D-39016 Magdeburg, Germany \\ $\ddagger$ Institut für Theoretische Physik, Eberhard-Karls-Universität \\ Auf der Morgenstelle 14, D-72076 Tübingen, Germany \\ (Received May 13, 2005, received in revised form July 06, 2005)
}

\begin{abstract}
The surfaces of icosahedral quasicrystals of an F-phase, orthogonal to a fivefold symmetry axis have a terrace-like appearance. On highly resolved images of these terraces one observes different local configurations. We search for possible corresponding configurations in the bulk model of atomic positions $\mathscr{M}$ based on the icosahedral tiling $\mathscr{T}^{*(2 F)}$.
\end{abstract}

\section{Introduction}

Clean and atomically flat surfaces $[1,2,3]$ of icosahedral quasicrystals, in particular the stable fivefold surfaces of icosahedral Al-Pd-Mn (i-AlPdMn), exhibiting flat terraces [1, 4, 5], have been investigated in the last years. On atomically resolved STM images some typical local configurations of atoms can be recognised $[6,7,8]$. It has been shown [2, 6], that the experimentally observed features are consistent with a bulk terminated structure [9]. Several typical local arrangements of atoms were found by various groups. Among these are the shapes that we call "ring", "white flower" and "dark star" configurations $[6,7,8]$. Using the bulk model of atomic positions $\mathscr{M}[6,10,11]$, based on the icosahedral tiling $\mathscr{T}^{*(2 F)}[12,13]$, we identify the corresponding configurations within the tiling as particular arrangements of Bergman clusters situated around the surface of an estimated fivefold termination. In this paper we determine the frequencies of so defined local arrangements of Bergman polytopes, knowing how the decoration by Bergman polytopes is coded within the icosahedral geometric model of atomic positions $\mathscr{M}$. The frequencies of these local configurations have to be determined and related to the particular fivefold terminations of the bulk model in a closed form, which is possible only in the orthogonal space $\mathbb{E}_{\perp}$. The position of the codings of the local configurations in $\mathbb{E}_{\perp}$ with respect to the maximumdensity plateau, which codes the terminations, the pairs of atomic planes $0.48 \AA$ apart, is shown[11] to be responsible for the formation of terraces in Fibonacci sequence and yields further insight into possible densities of these local arrangements within terraces, and once identified in the model, among them. In our approach we benefit from the fact, that the model $\mathscr{M}$ is a decoration of the canonical tiling $\mathscr{T}^{*(2 F)}$ so all the powerful tools from tiling analysis are at hand and applicable. Exemplary we derive the codings of the "ring" and the "white flower" configurations. A full featured analysis will be published elsewhere.

*Corresponding author. Email: Gerald.Kasner@Physik.Uni-Magdeburg.de 


\section{The "ring" and the "white flower" as arrangement of Bergman clusters}

One typical feature of stable terraces (formed by two atomic planes $0.48 \AA$ apart) are the Bergman clusters of dodecahedral shape, whose top pentagonal facets (with the central atom shifted $0.48 \AA$ into the bulk) are the motifs on this termination, see Figs $1 b$ and $2 b$. The edge length of the Bergman cluster (essentially a dodecahedron) is $3.0 \AA$, and consequently its height is $6.60 \AA$. The centers of these Bergman clusters are therefore located $3.3 \AA$ below the surface. The "ring" configuration, Fig.1a, we define as ten Bergman clusters attached to the vertices of a decagon, edge length $7.8 \AA$, Fig $1 \mathrm{~b}$. These ten surround always a central one, all eleven "hanging" below the surface. Note that this new definition of the "ring" is less restrictive than the previous one, from the reference [6].
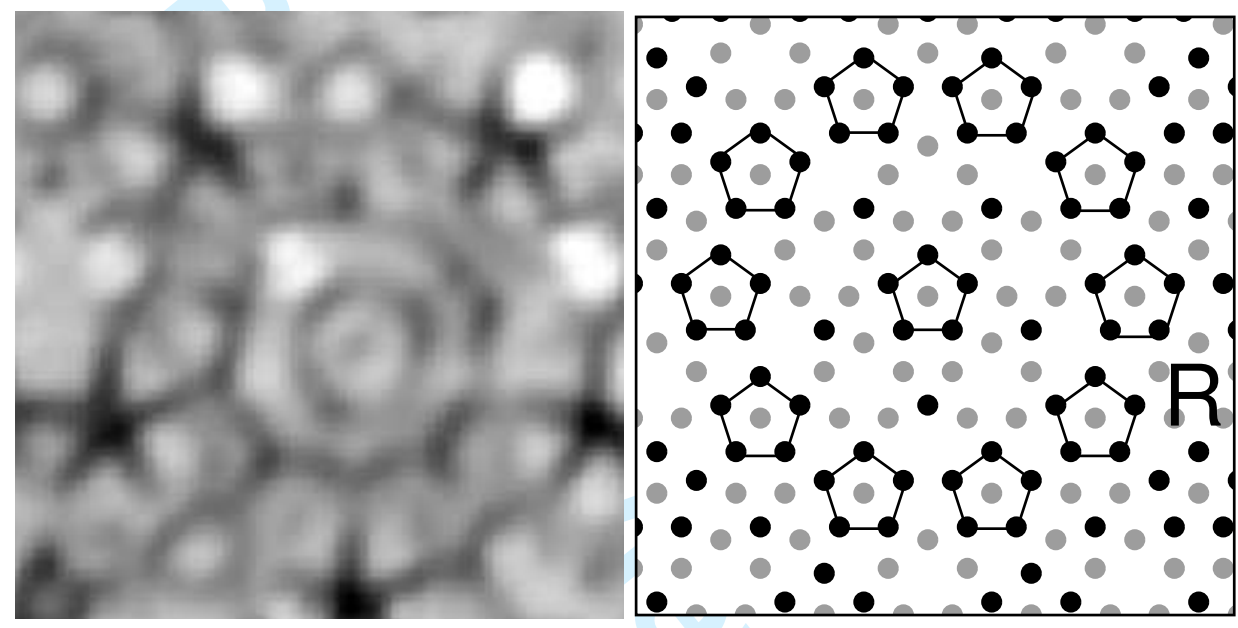

Figure 1: Left: A "ring" configuration in STM-scan [6]. Right: R-termination formed by two atomic planes. Black points form the top surface plane, whereas grey points form the plane $0.48 \AA$ A below. Indicated are the top pentagonal faces of ten Bergman clusters, which surround a central one. Compare it to the definition in [6].

In the similar manner the "white flower" is defined by five Bergman clusters "hanging" from the surface. These five Bergman polytopes are attached to a pentagon of the edge length $7.8 \AA$. Their upper faces, which are in the termination, are oriented as on the image, Fig.2b.

Having defined the "ring" and the "white flower" configurations as arrangement of Bergman clusters, we can now benefit from the fact, that model $\mathscr{M}$ is a decoration of the icosahedral tiling $\mathscr{T}^{*(2 F)}$ by Bergman and (automatically) Mackay clusters. Let us briefly recall how the Bergman clusters are used to decorate the tiling $\mathscr{T}^{*(2 F)}[10,14]$. In a first step, from the the tiling $\mathscr{T}^{*(2 F)}$ we locally derive the primitive or Amman-Kramer tiling $\mathscr{T}^{(P)}$. Through this procedure, the points in the tiling are exactly doubled. On new added vertices the Bergman polytopes are centered. Hence, in $\mathbb{E}_{\perp}$, the centers of Bergman polytopes are coded by the window $W_{a}$ of triacontahedral shape with edge length $\tau^{-1}$ (5) with (5)= $1 / \sqrt{2}$, for notation see [15]. 

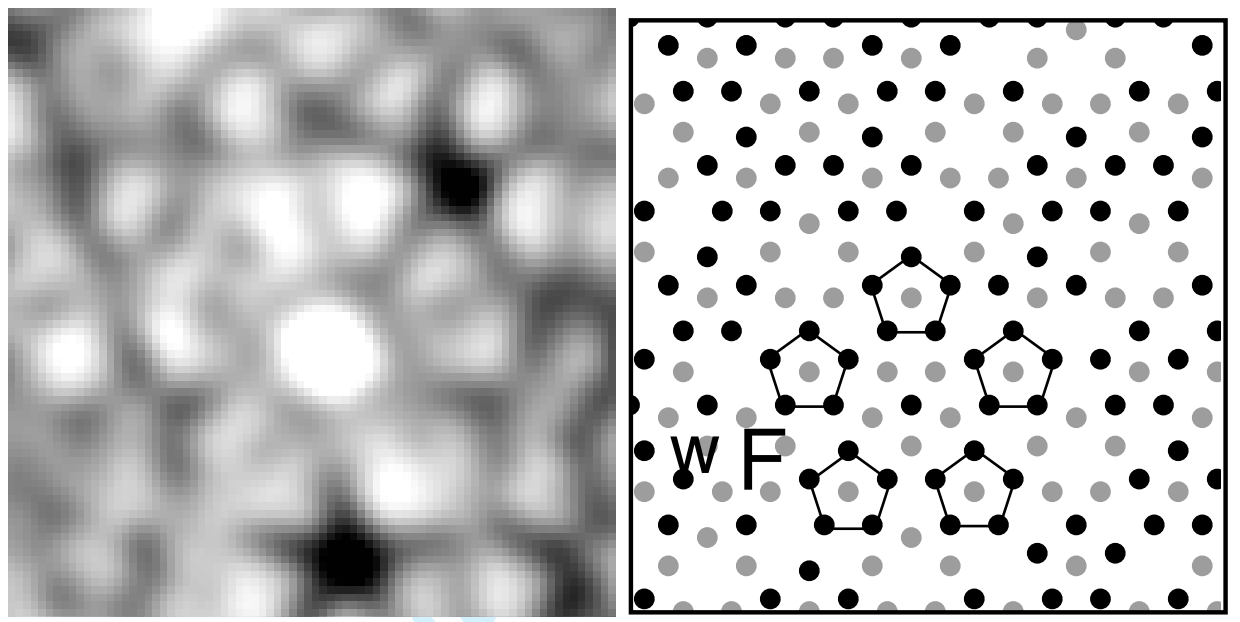

Figure 2: Left: The "white Flower" configuration in STM-scan [6], see also Fig.3b in [5]. Right: Indicated are the top pentagonal faces of five Bergman clusters [6]

\section{Calculation of the coding polytopes}

The arrangement of Bergman clusters, which define the "ring" and the "white flower" are now translated via the $\star$-map [16] into the perpendicular space $\mathbb{E}_{\perp}$, where we determine the coding polytopes of the respective configurations.
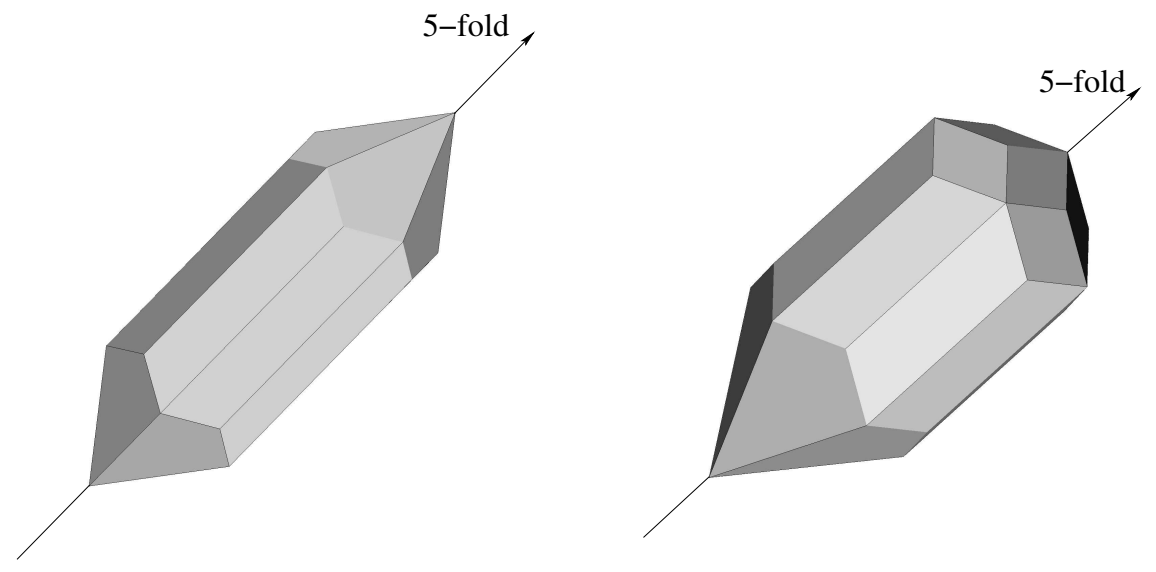

Figure 3: Coding polytopes of the "ring" (left) and the "white flower" (right) motives on the surface. The fivefold axes are indicated. 
The codings of the "ring" and the "white flower" configurations are a cigar-shaped and a pencil-shaped convex polytope, respectively, cf. Fig.3.

The shape of these coding polytopes and their positions in $\mathbb{E}_{\perp}$ define the frequencies of the corresponding motives on the terminations.

\section{Frequencies of the motives}

The maximum possible frequencies of the "ring" and "white flower" configuration are easily calculated from their coding polytopes. The cross sectional area perpendicular to the fivefold axis is proportional to the frequency of the corresponding motif. The absolute scale is given by the maximum cross sectional area of one of the involved triacontahedra $W_{a}$, which corresponds to $1.26 \cdot 10^{-2} \AA^{-2}[17]$.

The maximum cross sectional area of the coding polytope of the "ring" is calculated to be $\tau^{-6}(\tau=(\sqrt{5}+1) / 2)$ times that of the triacontahedron, which results in a maximum frequency of the "ring" to be $7.04 \cdot 10^{-4} \AA^{-2}$, which means, that on a scan of size $100 \times 100 \AA^{2}$, one counts at most 7 "rings".

Analogously, the maximum cross sectional area of the coding polytope for the "white flower" is calculated to be $\tau^{2}$ times that of the "ring", which results in a maximum density of $18.4 \cdot 10^{-4} \AA^{-2}$, which means, that on a scan of size $100 \times 100 \AA^{2}$, one counts at most 18-19 "white flowers".

\section{Position of coding polytopes in $\mathbb{E}_{\perp}$}

Not only the size of the coding polytopes, but also their position in $\mathbb{E}_{\perp}$ is of importance for the surface terminations. By using a modified Bravais rule, we were able to show [11], that the fivefold terminations are caused by the maximum density plateau in a plot of the summed density of two planes $0.48 \AA$ apart. What about the frequency of the "ring" and the "white flower"? Are they most frequent on these high density terraces?

In order to answer these questions, we present a density plot the same way as in [11], extended by the frequency (density) of "ring" and "white flower" configuration. This enables us immediately to obtain the frequencies of both motifs on the $\mathrm{C}$ and R-terrace observed recently[11].

\begin{tabular}{|c|c|c|c|}
\hline $\begin{array}{c}\text { name of } \\
\text { motif }\end{array}$ & $\begin{array}{c}\text { frequency on C } \\
\text { in } 10^{-4} \AA^{-2}\end{array}$ & $\begin{array}{c}\text { frequency on R } \\
\text { in } 10^{-4} \AA^{-2}\end{array}$ & $\begin{array}{c}\text { maximum possible frequency } \\
\text { in } 10^{-4} \AA^{-2}\end{array}$ \\
\hline \hline "ring" & 7.04 & 0.186 & 7.04 \\
\hline "white flower" & 18.4 & 2.1 & 18.4 \\
\hline
\end{tabular}

Table 1: Calculated frequencies of the "ring" and the "white flower" motifs on terraces C and $\mathrm{R}$ compared to their maximum possible frequency.

N.B. that our definitions of the "ring" and the "white flower" are based exclusively on atomic positions. Dependent on the sort of atoms that will occupy these atomic positions, the motifs might not be recognised on the surface. Hence the determined frequencies are only the upper bounds of the real configurations that we expect to appear, under the assumption of the validity of the model $\mathscr{M}$.

We readily calculate, that the "ring" as well as the "white flower" motifs are at their maximum possible frequency on the C terrace, while the "ring" as well as the "white flower" 
are relatively rare on the $\mathrm{R}$ terrace. The $\mathrm{C}$ termination is such that it has an atomic density in a surface plane higher than in the plane $0.48 \AA$ below.

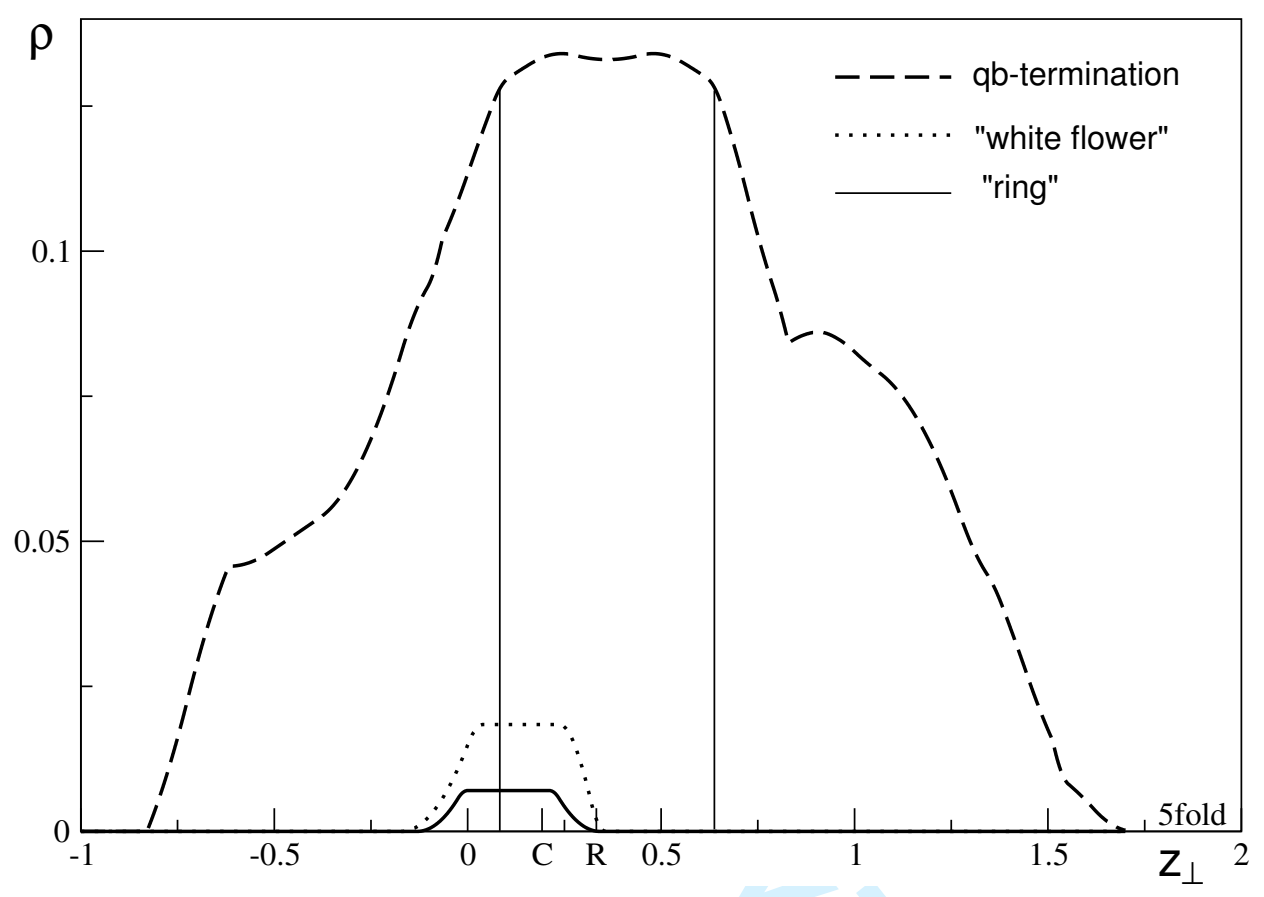

Figure 4: Density plot along the five-fold axis in $\mathbb{E}_{\perp}$. The atomic density of a qb-pair of planes is shown (dashes) together with the frequency of the "white flower" (dotted, enhanced by a factor 10) and the frequency of the "ring" (solid, enhanced by a factor 10). Positions of the $\mathrm{C}$ and $\mathrm{R}$ terraces are indicated, as well as the width of the plateau, which is responsible for the Fibonacci step structure $(\mathrm{S}=4.08 \AA, \mathrm{L}=6.60 \AA)$ among the terraces

According to the coding in $\mathbb{E}_{\perp}$ of the "rings" and "white flowers" (Fig 4), these configurations might appear also elsewhere in the bulk, and not only on the stable terminations, coded by the support of the plateau and framed in Fig 4.

The "ring" configuration has not yet been observed on a surface corresponding to a C plane. Two reasons are possible: either the contrast of a tenfold ring to the background on a $\mathrm{C}$ surface is not strong, or the chemistry on the ring configuration at a $\mathrm{C}$ plane is not appropriate.

We look forward to link our results to the variety of highly resolved STM images of the real fivefold surfaces. 


\section{References}

[1] T.M. Schaub, D.E. Bürgler, H.J. Güntherroth, and J.B. Suck. Phys. Rev. Lett., 73 1255 (1994).

[2] J. Ledieu, A.W. Munz, T.M. Parker, R. McGrath, R.D. Diehl, D.W. Delaney, and T.A. Lograsso. Surface Science, 433-435 666 (1999).

[3] J. Ledieu, C.A. Muryn, G. Thornton, R.D. Diehl, T.A. Lograsso, D.W. Delaney, and R. McGrath. Surface Science, 47289 (2001).

[4] Z. Shen, C.R. Stoldt, C.J. Jenks, T.A. Lograsso, and P.A. Thiel. Phys. Rev. B, 60 14688 (1999).

[5] L. Barbier, D. Le Floc' h, Y. Calvayrac, and D. Gratias. Phys. Rev. Lett., 88085506 (2002).

[6] Z. Papadopolos, G. Kasner, J. Ledieu, E.J. Cox, N. V. Richardson, Q. Chen, R.D. Diehl, T.A. Lograsso, A.R. Ross, and R. McGrath. Phys. Rev. B, 66184207 (2002).

[7] L. Barbier and D. Gratias. Progress in Surf. Science, 75177 (2004).

[8] B. Unal, T. A. Lograsso, A. Ross, C. J. Jenks, and P. A. Thiel. Phys. Rev. B, 71 165411 (2005).

[9] M. Gierer, M.A. Van Hove, A.I. Goldman, Z. Shen, S.-L. Chang, P.J. Pinhero, C.J. Jenks, J.W. Anderegg, C.-M. Zhang, and P.A. Thiel. Phys. Rev. B, 577628 (1998).

[10] G. Kasner and Z. Papadopolos. In E. Belin-Ferre, Patricia A. Thiel, An-Pang Tsai, and Knut Urban, editors, Quasicrystals, volume 643 of MRS Symposiom Proceedings, pages K9.7.1-K9.7.6, Warrendale, Pensylvania, 2001. Materials Research Society.

[11] Z. Papadopolos, P. Pleasents, G. Kasner, V. Fournée, C.J. Jenks, J. Ledieu, and R. McGrath. Phys. Rev. B, 69224201 (2004).

[12] P. Kramer, Z. Papadopolos, and D. Zeidler. J. Non-Cryst. Sol., 153 \& 154215 (1993).

[13] Z. Papadopolos, C. Hohnecker, and P. Kramer. Discrete Mathematics, 221101 (2000).

[14] G. Kasner, Z. Papadopolos, P. Kramer, and D.E. Bürgler. Phys. Rev. B, 603899 (1999).

[15] P. Kramer, Z. Papadopolos, and W. Liebermeister. In S. Takeuchi and T. Fujiwara, editors, Proceedings of the 6th International Conference on Quasicrystals, volume XLVII of Yamada Conference, pages 71-76, Singapore, 1998. World Scientific.

[16] R. V. Moody. In R. V. Moody, editor, The mathematics of Long-Range Aperiodic Order, page 403. Kluver, Dordrecht, 1997.

[17] P. Kramer, Z. Papadopolos, and H. Teuscher. J. Phys.: Condens. Matter, 112729 (1999). 
hiEabMägriziße \& Philosophical Magazin

1

2

3

4

5

6

7

8

9

ht10://mc.manuscriptcentral.com/pm-pm

11

12

10 


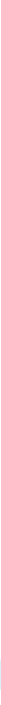



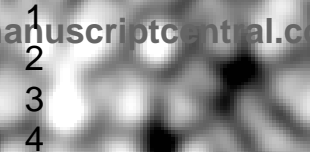


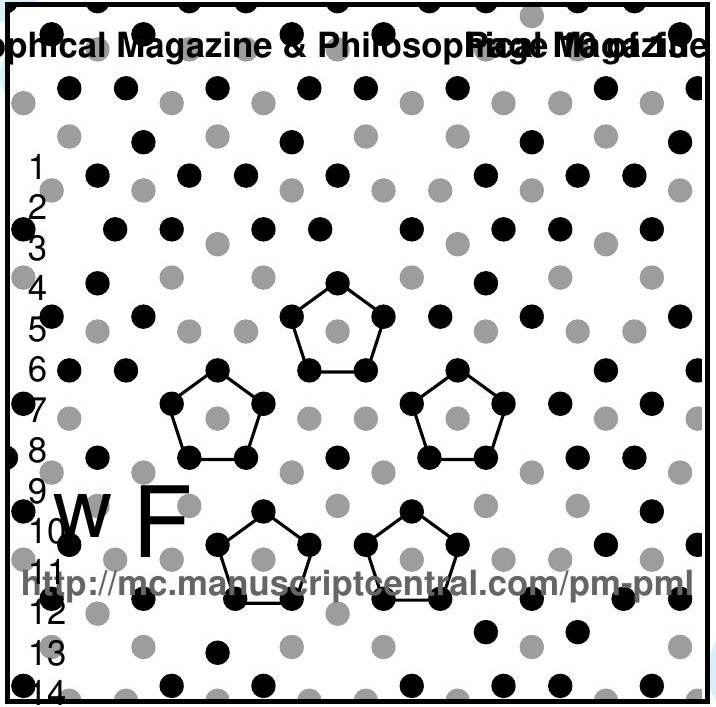




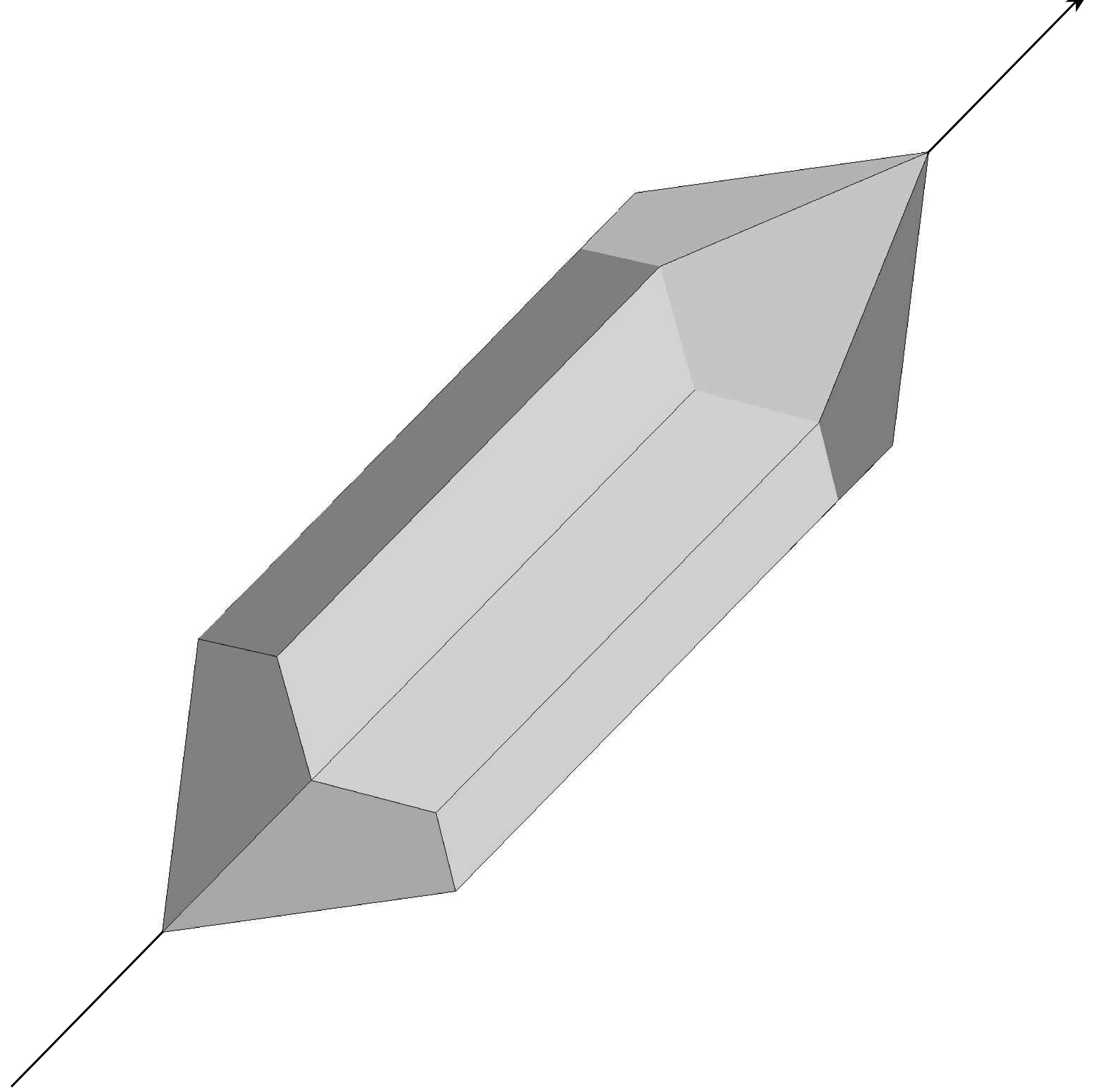




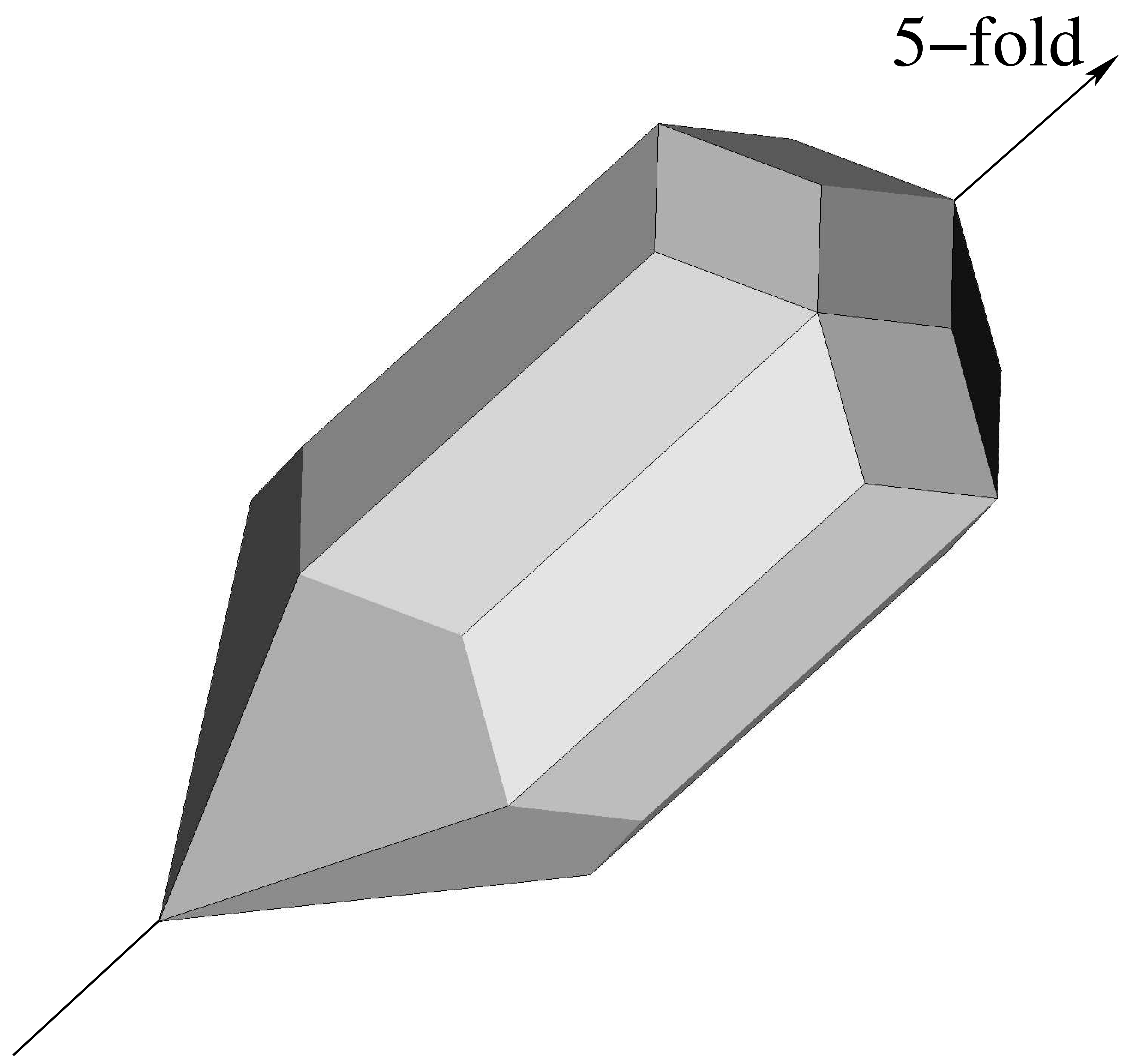




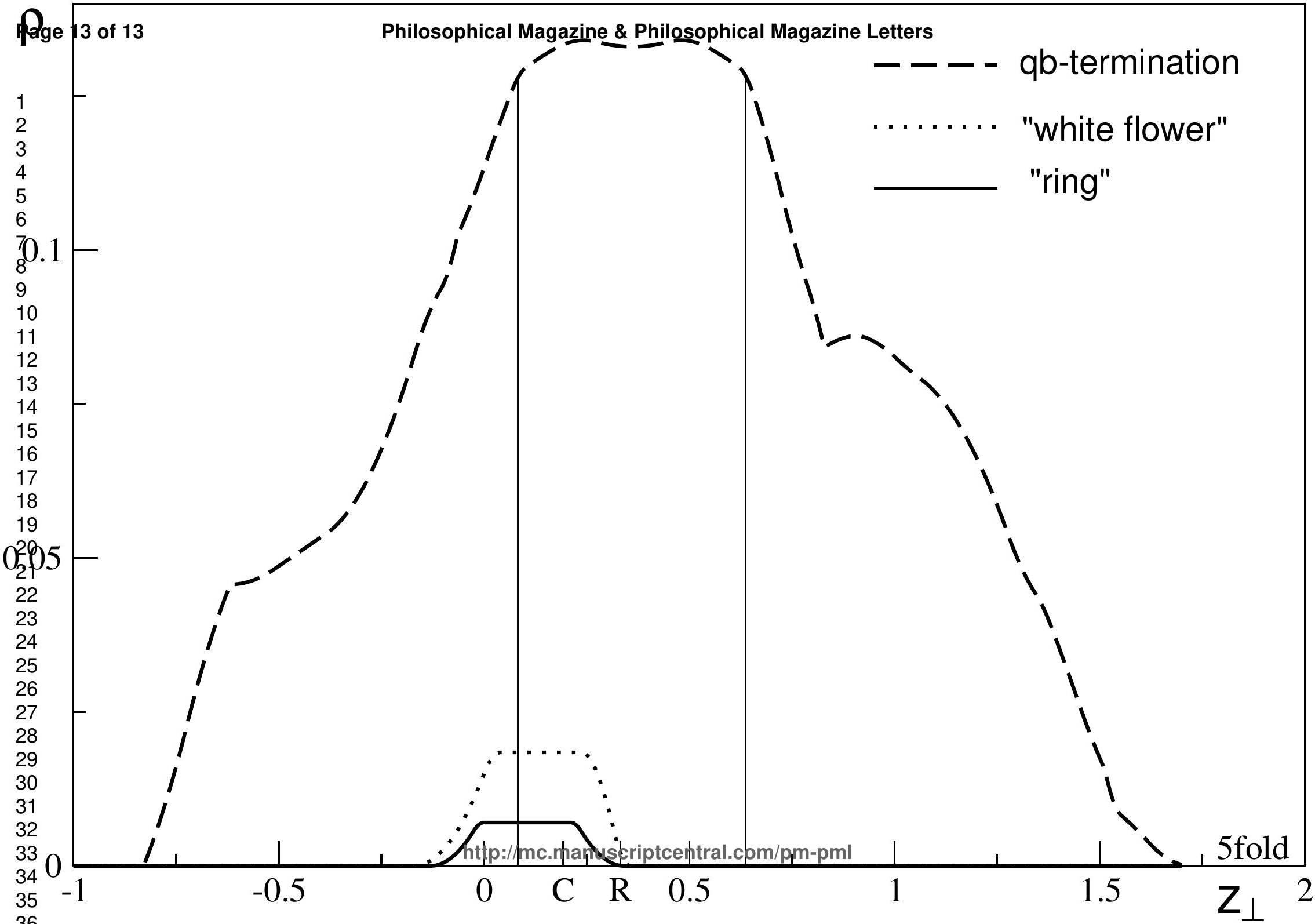

